\title{
Central control of brown adipose tissue
}

\section{By Nancy J. Rothwell, Department of Physiological Sciences, University of Manchester, Oxford Road, Manchester M13 9PT}

Thermogenesis is a term which can be used to describe any form of heat production, but is normally applied to adaptive or regulatory components of metabolic rate, namely non-shivering thermogenesis (NST) and diet-induced thermogenesis (DIT). NST and DIT are activated in response to physiological stimuli and are largely dependent on sympathetic activation of heat production in brown adipose tissue (BAT). The quantitative importance and thermogenic mechanisms of BAT will be reviewed by others participating in this symposium. The objective of the present review is to discuss our current knowledge of the central mechanisms involved in the control of BAT thermogenesis, and how they are affected by physiological or pathological conditions.

Of all aspects of BAT thermogenesis it is the central control which is probably the least understood, partly as a result of its complexity, but also because it has received relatively little direct attention. Considerable information and insight into this area can, however, be gained from studies concerned with feeding behaviour and temperature regulation, both of which are closely related and show many common features with sympatheticallymediated thermogenesis. Over the past few years, our understanding of central thermogenic mechanisms has improved considerably, due mainly to studies specifically designed to investigate this problem.

\section{Areas of the brain controlling $B A T$}

The hypothalamus is the major area concerned with the control of autonomic functions, particularly feeding behaviour and thermoregulation, and has been the primary focus for studies on BAT thermogenesis. A close association between the ventromedial hypothalamus $(\mathrm{VMH})$ and the regulation of body-weight or energy balance was first demonstrated almost 40 years ago, when destruction of the ventromedial nucleus was shown to result in hyperphagia and obesity. For a long time thereafter the VMH was referred to as a 'satiety' centre, acting reciprocally with the lateral hypothalamus (LH; known as the hunger centre) to control food intake (Stellar, 1954). However, obesity will develop in response to VMH lesions in the absence of hyperphagia, indicating that energy expenditure was simultaneously reduced (Han et al. 1965).

Shimazu \& Takahashi (1980) suggested that the VMH might directly affect metabolism of BAT, since lipogenesis in the tissue was increased by electrical stimulation of this, but not other hypothalamic regions in the rat. Perkins et al. (1981) then reported marked increases in thermogenesis (implied from measurements of temperature) of brown fat in response to VMH stimulation, which were dependent on the sympathetic nervous system. Several groups have now confirmed the involvement of the VMH in the control of BAT thermogenesis, and their findings are summarized in Table 1. VMH stimulation raises brown fat temperature in conscious as well as anaesthetized animals, it also causes marked and selective increases in noradrenaline turnover (approximately threefold; Saito et al. 1987), and blood flow (almost fiftyfold; Iwai et al. 1987) to BAT and $40 \%$ increases in resting oxygen consumption (Atrens et al. 1985). Holt et al. (1987) reported that genetically obese Zucker rats exhibited normal temperature responses of brown fat following electrical stimulation of the VMH. Freeman \& Wellman (1987) claimed that BAT was unresponsive to VMH stimulation in normal rats, but observed 
Table 1. Effects of stimulation or destruction of the ventromedial hypothalamus (VMH) on brown adipose tissue (BAT) thermogenesis

\author{
Electrical stimulation of the VMH causes: \\ Increased: Lipogenesis-lipolysis in BAT \\ Temperature of BAT \\ BAT noradrenaline turnover \\ Firing rate of sympathetic nerves to BAT \\ Blood flow to BAT \\ Whole-body oxygen consumption \\ Destruction-inhibition of the VMH causes: \\ Reduced: Noradrenaline turnover in BAT \\ Firing rate of nerves to $\mathrm{BAT}$ \\ GDP binding in BAT mitochondria \\ Thermogenic responses to carbohydrate
}

increases in temperature following stimulation of other hypothalamic sites. However, closer study of their findings indicates that positive responses were elicited from the lateral region of the VMH (Freeman \& Wellman, 1987), the same area that Perkins et al. (1981) found to be most sensitive. Many effects of VMH lesions, which were previously ascribed to destruction of the nucleus, have now been associated with disruption of the ventral noradrenergic bundle (VNAB) which passes through the lateral region of the VMH. Stimulation of this nerve bundle rather than the nucleus itself may be responsible for the observed effects on brown fat (Gold et al. 1977).

Inhibition of thermogenesis following surgical or chemical destruction of the VMH has been inferred from increases in the efficiency of weight gain (Han et al. 1965; Han, 1968), reduction in the acute thermogenic responses to food (Carlisle et al. 1988), in noradrenaline turnover and thermogenic activity of brown fat (Seydoux et al. 1981; Hogan et al. 1982; Yoshida et al. 1983; Niijima et al. 1984) all of which are reduced and probably contribute to the development of obesity. Once again it is difficult to distinguish the influence on thermogenesis of the VMH from that of the VNAB. Sahakian et al. (1983) have shown that depletion of noradrenaline in or around the VNAB stimulates food intake and weight gain, but inhibits BAT activity in the rat.

There is some debate on whether the VMH is involved in the control of NST as well as DIT, and this may again relate to differential effects of the nucleus and of noradrenergic fibres. Hogan et al. (1982) reported impaired DIT, but no deficiency of NST in VMH-lesioned rats, whereas Imai-Matsumura et al. (1984) demonstrated that injection of lidocaine into the VMH prevented the increase in BAT temperature in response to cooling of the preoptic area in conscious rats.

The VNAB runs along the base of the brain and projects to the paraventricular nuclei (PVN) and dorsomedial nuclei (DMN) and the preoptic region of the hypothalamus, all of which have been implicated in the control of brown fat thermogenesis (Table 2). The preoptic and anterior areas of the hypothalamus have been studied in some detail because of their general involvement in temperature regulation; both can apparently activate a variety of peripheral mechanisms of heat production and conservation (see Hammel, 1968). The PVN has been more specifically associated with dietary responses and its destruction results in obesity that shares some common features with the VMH syndrome, although PVN-induced obesity is generally more modest (Leibowitz, 1978; Weingarten et al. 1985). 
Table 2. Effects of electrical stimulation on brown adipose tissue (BAT) temperature

$\begin{array}{lcc}\text { Brain area } & \text { BAT temperature } & \text { Reference } \\ \text { VMH } & +++ & * \dagger \\ \text { VMH } & + & \ddagger \\ \text { PVN } & ++ & \neq 8 \\ \text { POAH } & ++ & \ddagger \neq 8 \\ \text { SCN } & + & 8 \\ \text { SON } & + & \dagger \\ \text { SON } & - & 8 \\ \text { PH } & - & 8 \\ \text { PMV } & - & \neq 8 \\ \text { DPM } & - & 8 \\ \text { DMN } & - & +8 \\ \text { PAG } & - & 8 \\ \text { ARH } & - & \ddagger \\ \text { Raphe } & - & 8 \\ \text { VTN } & - & \ddagger \\ \text { LH } & - & \dagger\end{array}$

,+ Rise in temperature; - , fall in temperature or no response. VMH, ventromedial hypothalamus; PVN, paraventricular nucleus; POAH, preoptic anterior hypothalamus; SCN, suprachiasmatic nucleus; SON, supraoptic nucleus; PH, posterior hypothalamus; PMV, ventral premammillary nucleus; DPM, dorsal premammillary nucleus; PAG, periaqueductal grey; ARH, arcuate nucleus; VTN, ventromedial tegmental nucleus; LH, lateral hypothalamus.

*Perkins et al. (1981).

tHolt et al. (1987).

†Freeman \& Wellman (1987).

\$R. A. LeFeuvre, N. J. Rothwell and M. J. Stock, unpublished results.

Many of the areas that activate BAT (Table 2) have already been associated with the control of thermogenesis or closely related functions. For example, the suprachiasmatic nucleus is thought to be responsible for diurnal variations in body temperature, while the supraoptic nucleus is involved in arousal from hibernation. The supraoptic nucleus is particularly sensitive to insulin and has been proposed as an integrator between endocrine feedback and the autonomic nervous system (Posner, 1987).

Investigations into the involvement of extrahypothalamic areas in the control of thermogenesis are somewhat limited. Activation of thermogenesis in response to conditioning (e.g. at the time of darkness) in laboratory rats and the sight and smell of food (see Rothwell \& Stock, 1981, 1986a,b) suggests that there is some cortical influence on thermogenesis presumably via the hypothalamus.

Stereotaxic knife cuts or suction decerebration in the cat or the rat have indicated the presence of a tonic inhibitory centre in the upper pontine region. High-level decerebration in the prepontine region produces dramatic increases in body temperature $\left(3-4^{\circ}\right)$ in several species (Bignall et al. 1975; Chambers et al. 1974; Rothwell et al. 1983a). In the rat, this is associated with dramatic increases in metabolic rate (Rothwell et al. 1983a) and blood flow to brown fat (Shibata et al. 1987), which are dependent on the sympathetic nervous system. In contrast, premammillary transections prevent or inhibit these responses indicating the presence of a tonic inhibitory system located somewhere between the lower mid-brain and upper pons which controls sympathetic outflow (Benzi \& Girardier, 1986; Rothwell et al. 1983a; Shibata et al. 1987). 
An alternative approach to the identification of brain areas associated with the control of thermogenesis is to follow metabolic activity in the brain from uptake of radiolabelled 2-deoxy-D-glucose in response to a thermogenic stimulus. Morimoto \& Murakami (1985) used this technique in animals exposed to hypothalamic or peripheral thermal stimulation. They observed changes in activity in a number of brain areas, but particularly the red nucleus, several areas of the thalamus, the $\mathrm{VMH}$, areas of the basal ganglia and sensory cortex, all of which were stimulated in response to hypothalamic cooling. However, no direct measurements of thermogenesis or BAT activity were made in this study.

Several pieces of evidence have implicated central noradrenergic pathways in the control of thermogenesis. The study of Sahakian et al. (1983) quoted earlier demonstrated that chemical destruction of noradrenergic pathways in the region of the VNAB resulted in inhibition of BAT activity and obesity. Conversely, Shimazu et al. (1986) have observed dramatic increases in body-weight gain in rats in which noradrenaline was continuously infused into the VMH over several weeks. Although no direct measurements of food intake or thermogenesis were included in this study, a reduction in BAT activity was assumed from the decrease in triglyceride turnover (Shimazu et al. 1986). After 12 weeks, food intake was increased by $67 \%$ in infused rats, but they were already $66 \%$ heavier by this time. The same group of workers found no changes in body-weight in response to noradrenaline infusion into the PVN or the lateral hypothalamus, and only modest obesity in response to adrenaline infusion into the VMH. These apparently conflicting findings of Sahakian et al. (1983) and Shimazu et al. (1986) may represent subtle but crucial differences in the site of infusion and the location and type of receptors affected by experimental manipulation. For example, microinjection of noradrenaline into the PVN can elicit feeding via an $\alpha$-adrenoreceptor mechanism (Liebowitz, 1978), whereas activation of $\beta$-adrenoreceptors on the lateral hypothalamus may inhibit feeding (Grossman, 1962). It is likely that the control of thermogenesis is also dependent on both the site and on receptor subtype. Changes in noradrenaline concentration or turnover, and particularly the ratio of activities, noradrenergic: serotonergic pathways within the hypothalamus, are considered of primary importance in the regulation of body temperature (Myers, 1972). These effects have been studied mainly within the preoptic region, but once again conflicting results have been obtained which are highly species dependent.

The reported effects of serotonergic pathway on thermogenesis are slightly less controversial. Central injections of 5-hydroxytryptamine (5HT), serotonergic agonists or releasing agents such as $\mathrm{D}$-fenfluramine stimulate metabolic rate and BAT thermogenesis by increasing sympathetic outflow (R. A. LeFeuvre and N. J. Rothwell, unpublished results). Chemical depletion of $5 \mathrm{HT}$ pathways by injection of parachlorophenylalanine (PCPA) inhibits BAT activity (Fuller et al. 1987) and causes hyperphagia and obesity in the rat (Breisch et al. 1976). However, central injection of the slightly more selective neurotaxic agent 5,7-dihydroxytryptamine (5,7-DHT), in combination with desipramine to protect noradrenergic pathways, fails to induce obesity but greatly enhances the thermogenic effects of $D$-fenfluramine, presumably because of increased receptor density or enhanced receptor sensitivity (R. A. LeFeuvre and N. J. Rothwell, unpublished results). Presumably the varied effects of PCPA and 5,7-DHT are due to selective destruction of $5 \mathrm{HT}$ pathways in different brain regions. It has been reported that serotonergic pathways within the Raphe nucleus are not destroyed by 5,7-DHT (Fischette et al. 1987) and these are probably involved in the control of feeding and body-weight (Coscina \& Magder, 1984).

There are relatively few studies on dopaminergic or cholinergic pathways and 
thermogenesis, although Shimazu et al. (1986) observed no changes in body-weight after chronic infusions of acetylcholine into the hypothalamus.

Increasing brain $\gamma$-amino- $n$-butyric acid (GABA) concentrations by peripheral administration of GABA transaminase (4-aminobutyrate aminotransferase; $E C$ 2.6.1.19) inhibitors prevents the development of genetic obesity (Coscina \& Nobrega, 1984) and stimulates thermogenesis (Horton et al. 1988b). The use of selective GABA agonists and antagonists, injected centrally (into the $\mathrm{VMH}$ or third ventricle) has shown that activation of $\mathrm{GABA}_{B}$ receptors, for example by Baclofen, causes very large increases in thermogenesis, whereas activation of the $G A B A_{A}$ receptor inhibits metabolic rate and BAT activity (Horton et al. 1988a).

The past 5 years have seen an explosive increase in the number of peptides which have been identified within the brain, quite a number of these have been found to either exert direct thermogenic effects or have in some way been implicated in the control of energy balance (Table 3). Limitations on space prevent a full description of each of these peptides and their involvement in thermogenesis, but some have been discussed in detail elsewhere. It is, therefore, appropriate to consider only those of established importance or of most recent interest.

The involvement of insulin in the regulation of energy balance has been known for many years, but its central actions and.stimulating effects on thermogenesis are more recent and remain somewhat controversial. The origins and physiological role of insulin within the brain are still largely unknown, although there is ample information indicating central effects on body-weight (and indirectly on thermogenesis) which have recently been reviewed in detail (Baskin et al. 1987; Posner, 1987; Rothwell \& Stock, 1988). Physiological responses to insulin are complex and varied and the results of experimental studies are often conflicting. This is probably because of the apparently opposite effects of insulin: peripherally to stimulate feeding and possibly inhibit thermogenesis, and centrally where it usually inhibits feeding and may increase energy expenditure (see previously mentioned reviews). An illustration of these diverse effects is seen in

\section{Table 3. Thermogenic effects of peptides}

\begin{tabular}{|c|c|}
\hline Marked effects & \\
\hline $\begin{array}{l}\text { CRF } \\
\text { TRH } \\
\text { TRH analogues (e.g., RX77368) }\end{array}$ & $\begin{array}{l}\text { Interleukin-1 } \beta, 1 \alpha \\
\text { DADLE } \\
\text { CCK-4 }\end{array}$ \\
\hline $\begin{array}{l}\text { Modest effects } \\
\text { Somatostatin } 28 \\
\text { NPY } \\
\text { Bombesin } \\
\text { Neurotensin }\end{array}$ & $\begin{array}{l}\text { TNF } \alpha \\
\text { PGE }_{1} \\
\text { PGE }_{2}\end{array}$ \\
\hline $\begin{array}{l}\text { No effects } \\
\text { CCK-8 } \\
\text { Peptide YY } \\
\text { Leu-enkephalin }\end{array}$ & $\begin{array}{c}\text { VIP } \\
\text { GABA }\end{array}$ \\
\hline
\end{tabular}

CRF, corticotrophin-releasing hormone; TRH, thyrotropin-releasing hormone; NPY, neuropeptide Y; DADLE, D-ala-D-leu enkephalin; CCK-4, cholecystokinin quatropeptide; CCK-8, cholecystokinin octapeptide; TNF $\alpha$, tumour necrosis factor $\alpha ; P_{1} E_{1}$ and $P_{G E}$, prostaglandins $E_{1}$ and $E_{2} ;$ VIP, vasoactive intestinal peptide; GABA, $y$-amino- $n$-butyric acid. 
genetically obese rodents which are severely hyperinsulinaemic, but show reduced concentrations of insulin within the cerebrospinal fluid (Baskin et al. 1985). Furthermore it seems that very high doses of insulin, administered by either route, will inhibit thermogenesis if they result in hypoglycaemia (Rothwell \& Stock, 1988).

A number of other gastrointestinal peptides which are found within the central nervous system influence food intake (for review, see Figlewicz et al. 1987), and some also stimulate thermogenesis. It is interesting to observe that cholecystokinin quatropeptide (CCK-4) causes large increases in $\mathrm{O}_{2}$ consumption when injected intracerebroventricularly in the rat, whereas CCK-8 causes no effect or a slight inhibition ( $R$. A. LeFeuvre and N. J. Rothwell, unpublished results).

Corticotrophin-releasing factor (CRF) is a very potent activator of thermogenesis and BAT activity (LeFeuvre et al. 1987). This thermogenic effect of CRF is not dependent on the pituitary, and may be responsible for the enhanced thermogenesis that follows adrenalectomy (Holt et al. 1988). Increased sensitivity to the inhibitory effects of glucocorticoids, possibly at the hypothalamic level, has been proposed as a primary cause of defective thermogenesis in genetically obese animals (LeFeuvre et al. 1987; Rothwell \& Stock, 1986a,b; York, 1987). However, the genetically obese Zucker rat can respond normally to exogenous CRF and has comparable concentrations of the peptide to lean animals (Carnie et al. 1988).

Another hypothalamic releasing hormone, thyrotropin-releasing hormone (TRH) also has potent effects on thermogenesis (Griffiths et al. 1988). TRH causes arousal, and may be responsible for the increase in heat production during arousal from hibernation (Stanton et al. 1980). Several analogues of TRH are even more effective as thermogenic agents, possibly because of their greater stability (Griffiths, 1987). Considerable interest has been generated in an 'anorexigenic peptide' which has a structure similar to that of TRH (glu-his-gly) and inhibits feeding behaviour (Myers et al. 1983). Indirect evidence (weight loss in the absence of hypophagia) suggests that this too may stimulate metabolic rate (Myers et al. 1983).

Enkephalins and endorphins have established actions on body temperature and feeding, and some also affect thermogenesis. McLaughlin \& Baile (1985) reported hyperphagia and obesity in rats immunized against $\beta$-endorphin and claimed that this provided evidence that $\beta$-endorphin is a satiety hormone. However, food intake over the 12 -week study was elevated by less than $5 \%$, and this was probably secondary to the very large $(22-85 \%)$ increases in body-weight gain. We have observed small increases in thermogenesis in rats injected with met or leu enkephalin, but much larger responses to D-ala-D-leu enkephalin (DADLE) which acts on $\delta$-opioid receptors (R. A. LeFeuvre and N. J. Rothwell, unpublished results). If this effect represents a physiological response to activation of the $\delta$-receptor it is somewhat unusual, since most substances that are thermogenic tend to inhibit feeding, whereas DADLE increases food intake (Tepperman \& Hirst, 1983).

All the peptides discussed previously apparently stimulate thermogenesis, but it is much more difficult to demonstrate an inhibitory effect. Several peptides induce hypothermia (e.g. bombesin, neurotensin), but none that we have tested so far reduces $\mathrm{O}_{2}$ consumption in normal animals. It is likely that any inhibitory effects will be apparent only in conditions where thermogenesis is already activated, for example, by cold or hyperphagia.

\section{Physiological stimuli to thermogenesis}

Exposure to cold apparently provides the most potent physiological stimulus to thermogenesis, at least in laboratory animals. Afferent signals for NST derive from 
temperature-sensitive neurons within the hypothalamus and from thermal inputs from the peripheral, and these processes have been reviewed in some detail (Hammel, 1968).

Afferent signals responsible for activating DIT are largely unknown and probably much more complex. For example, it seems that DIT can be stimulated to varying extents by the ingestion of several, if not all, the major nutrients, as well as by increases in total food intake and the consumption of protein-deficient diets (for reviews, see Rothwell \& Stock, 1986a,b). Furthermore, if DIT is directly involved in the regulation of energy balance it is possible that some signal relating to the size of body energy stores could also influence thermogenesis, though none has yet been identified.

Ingestion of carbohydrate and fat both increased sympathetic activity (see Landsberg \& Young, 1983; Landsberg, 1986) and thermogenesis acutely (Rothwell et al. 1982) and chronically (Rothwell et al. 1983b) in experimental animals. Little if any information exists on the central effects of individual nutrients on thermogenesis, but some effects can be inferred from studies of food intake or body temperature. For example, there are numerous glucose-sensitive sites within the hypothalamus, particularly in the VMH (Oomura, 1976). Shiraishi \& Mager (1980) demonstrated the glucopenia induced by microinjections of 2-deoxy-D-glucose caused hypothermia in the rat, and the most sensitive area was the ventral premammillary nucleus. Davis et al. (1981) reported that continuous intracerebroventricular infusions of glucose, glycerol or $\beta$-hydroxybutyrate caused substantial weight loss over $84 \mathrm{~d}$ in rats, with only small reductions in food intake. In the case of $\beta$-hydroxybutyrate, weight loss occurred on a normal food intake, and in a limited number of preliminary studies we have observed increases in BAT temperature following intracerebroventricular injection of this substance in the rat (R. A. LeFeuvre and N. J. Rothwell, unpublished results).

Oomura (1987) has described marked effects on feeding behaviour of several endogenous sugar acids and suggested that these may be involved in the regulation of body-weight. Other nutrients that act as substrates for brain metabolism and could, therefore, directly affect thermogenesis have been reviewed by Williamson (1987), but no effects on metabolic rate have as yet been reported. In addition to direct central actions, feeding may activate neural or humoral signals. One of the most obvious of these, which has been discussed earlier, is insulin.

Protein deficiency causes large increases in DIT and brown fat activity which are not related to increases in carbohydrate or fat intake (Rothwell \& Stock, 1987b). Lowprotein diets increase the ratio, circulating tryptophan: other large neutral amino acids which compete for brain uptake (see Leathwood, 1987). Increased availability of tryptophan will stimulate synthesis of $5 \mathrm{HT}$, particularly within the PVN (Fernstrom, 1983). This was proposed as a mechanism by which specific appetite for protein and carbohydrate is controlled (for review, see Leathwood, 1987). However, the same process could activate DIT in response to protein deficiency. The elevated metabolic rates of rats fed on low-protein diets are prevented by antagonists of 5HT (Rothwell \& Stock, 1986b), and dietary supplementation of tryptophan can stimulate BAT activity (N. J. Rothwell and M. J. Stock, unpublished results), which would support this hypothesis.

\section{Pathophysiological effects on thermogenesis}

It is now well established that obesity in laboratory animals, particularly the inherited conditions, are dependent on defective thermogenesis, probably resulting from a defect in central control mechanisms or afferent signals (for review, see York, 1987). This problem will be discussed in detail by other speakers in this symposium, and in the present context it is sufficient to say that no single defect has been clearly identified as a 
primary cause of genetic obesity, and it has been difficult to distinguish secondary effects of the obesity from primary factors which may influence thermogenesis.

In addition to the effects of diet and cold discussed previously, several other stimuli may affect thermogenesis, such as injection, injury, trauma or stress. The fever induced by injection of bacterial endotoxin in the rat is dependent on sympathetically mediated increases in metabolic rate and brown fat activity (Jepson et al. 1987). Peripheral or central injection of interleukin-1 $\beta$, now considered to be the main endogenous pyrogen, causes even more dramatic increases in thermogenesis and BAT activity (Dascombe et al. 1987), which are dependent on release of CRF (Rothwell, 1989). Genetically obese Zucker rats show diminished febrile responses to endotoxin (Grimble \& Holden, 1987) and fail to increase fever, $\mathrm{O}_{2}$ consumption or brown fat activity in response to interleukin-1 $\beta$ (Dascombe et al. 1988), possibly because of a failure to release CRF. Another cytokine which induces fever and exhibits thermogenic effects when injected centrally is tumour necrosis factor $\alpha$ (TNF $\alpha$ ) (Coombes et al. 1987). This peptide has been implicated in fever and endotoxic shock, and is identical to cachectin which has been considered responsible for many of the cachectic responses associated with cancer (see Beutler \& Cerami, 1986). TNFo causes less dramatic effects on thermogenesis than interleukin, which are not dependent on CRF release (N. J. Rothwell, unpublished results), but may be involved in the stimulation of brown fat observed in tumour-bearing animals exhibiting cachexia (Brooks et al. 1981). Febrile effects of TNF $\alpha$ and interleukin are dependent on release of prostaglandins which themselves elicit large increases in fever (Cooper, 1987) and thermogenesis (Rothwell \& Stock, 1988b). Recent findings (Morimoto et al. 1988) have indicated that the $\mathrm{VMH}$ is more sensitive to prostaglandins than other hypothalamic areas, including the preoptic anterior hypothalamus. This finding may explain why destruction of the VMH inhibits endotoxin fever (Seydoux et al. 1985), but also has interesting implications for the site of action of endotoxin or peripherally released interleukin, which are thought to be unable to cross the bloodbrain barrier but which could act at sites within the VMH. There is also some evidence to suggest an involvement of prostaglandin in DIT, since $\mathrm{O}_{2}$ consumption of overfed rats is inhibited by cyclooxygenase inhibitors (Rothwell \& Stock, 1986c).

\section{Conclusions}

Our knowledge of the central control of thermogenesis has increased dramatically over the past few years. Several major hypothalamic areas and neurotransmitter pathways have now been identified and it is possible, albeit somewhat speculative, to link known thermogenic effects with central mechanisms. It is thus tempting to construct fairly grand and complex schemes describing central mechanisms and their inter-relations which have the useful effect of clarifying our current knowledge. However, these tend to detract from the more numerous areas of ignorance of even the most simple processes (e.g. how, why and where do ingested nutrients act to increase sympathetic outflow). It is hoped that the present brief review has highlighted such areas of ignorance as well as summarizing some of our current knowledge in the central mechanisms controlling thermogenesis.

The author is grateful to The Royal Society, the MRC and The Wellcome Trust for financial support for this work. 


\section{REFERENCES}

Atrens, D. M., Sinden, J. D., Penicaud, L., Devos, M. \& LeMagnen, J. (1985). Physiology and Behavior 35, 15-20.

Baskin, D. G., Figlewicz, D. P., Woods, S. C., Porte, D. \& Dorsa, D. M. (1987). Annual Review of Physiology $49,335-347$.

Baskin, D. G., Porte, D., Guest, K. \& Dorsa, D. M. (1985). Life Sciences 36, 627-633.

Benzi, R. H. \& Girardier, L. (1986). Pflugers Archiv 406, 37-44.

Beutler, B. \& Cerami, A. (1986). Nature 320, 584-588.

Bignall, K. E., Heggenness, F. W. \& Palmer, J. E. (1975). Experimental Neurology 49, 174-188.

Breisch, S. T., Zemlan, F. P. \& Hoebel, B. G. (1976). Science 192, 382-384.

Brooks, S. C., Neville, A. M., Rothwell, N. J., Stock, M. J. \& Wilson, S. (1981). Bioscience Reports 1, 509-513.

Carlisle, H. J., Rothwell, N. J. \& Stock, M. J. (1988). Proceedings of the Nutrition Society 47, 24A.

Carnie, J. A., LeFeuvre, R. A., Linton, E. A., McCarthy, D. \& Rothwell, N. J. (1988). Proceedings of the Nutrition Sociery 47, 165A.

Chambers, W. W., Siegel, M. S., Liu, J. C. \& Liu, C. N. (1974). Experimental Neurology 42, 282-299.

Coombes, R. C., Rothwell, N. J., Shah, P. \& Stock, M. J. (1987). Bioscience Reports 10, 791-799.

Cooper, K. E. (1987). Annual Review of Neuroscience 10, 297-324.

Coscina, D. V. \& Magder, R. J. (1984). Physiology and Behavior 33, 575-579.

Coscina, D. V. \& Nobrega, J. N. (1984). Intemational Journal of Obesity 8, Suppl. 1, 191-200.

Dascombe, M. J., Hardwick, A. J., LeFeuvre, R. A. \& Rothwell, N. J. (1988). Journal of Physiology 403, 41P.

Dascombe, M. J., LeFeuvre, R. A., Rothwell, N. J., Sagay, B. O. \& Stock, M. J. (1987). British Journal of Pharmacology 92, 624.

Davis, J. D., Wirtschaffer, D., Asin, K. E. \& Brief, D. (1981). Science 212, 81-82.

Fernstrom, J. D. (1983). Physiological Review 63, 484-546.

Figlewicz, D. P., Lalour, F., Sipis, A., Porte, D. \& Woods, D. (1987). Annual Review of Physiology 49, 383-395.

Fischette, C. T., Nock, B. \& Renner, K. (1987). Brain Research 421, 263-279.

Freeman, P. H. \& Wellman, P. J. (1987). Brain Research Bulletin 18, 7-11.

Fuller, M. J., Stirling, D. M., Dunnett, S., Reynolds, G. P. \& Ashwell, M. (1987). Bioscience Reports 7, 121-127.

Gold, R. M., Jones, A. P., Sawchenko, P. E. \& Kapatos, G. (1977). Physiology and Behavior 18, 1111-1119.

Griffiths, E. C. (1987). Clinical Science 73, 449-457.

Griffiths, E. C., Rothwell, N. J. \& Stock, M. J. (1988). Experientia 44, 41-42.

Grimble, R. F. \& Holden, D. (1987). Proceedings of the Nutrition Society 46, 105-117.

Grossman, S. P. (1962). American Joumal of Physiology 241, R173-R184.

Hammel, H. T. (1968). Annual Review of Physiology 30, 641-710.

Han, P. N., Lin, C. H., Mu, J. Y. \& Lui, A.-C. (1965). American Journal of Physiology 209, 627-631.

Han, P. W. (1968). American Journal of Physiology 215, 1343-1350.

Hogan, S., Coscina, D. V. \& Himms-Hagen, J. (1982). American Joumal of Physiology 243, E334-E338.

Holt, S., Rothwell, N. J., Stock, M. J. \& York, D. A. (1988). American Joumal of Physiology 254, E163-E166.

Holt, S. J., Wheal, H. \& York, D. A. (1987). Brain Research 405, 227-233.

Horton, R. W., LeFeuvre, R. A., Rothwell, N. J. \& Stock, M. J. (1988a). Neuropharmacology 27, 363-366.

Horton, R., Rothwell, N. J. \& Stock, M. J. (1988b). General Pharmacology 19, 403-405.

Imai-Matsumura, K., Matsumura, K. \& Nakayama, T. (1984). Japanese Journal of Physiology 34, 939-943.

Iwai, M., Hill, N. S. \& Shimazu, T. (1987). Pfiugers Archiv 410, 44-47.

Jepson, M. M., Cox, M., Bates, P. C., Rothwell, N. J., Stock, M. J., Cady, E. B. \& Millward, D. J. (1987). American Journal of Physiology 252, E581-E587.

Landsberg, L. (1986). Quarrerly Journal of Medicine 236, 1081-1090.

Landsberg, L. \& Young, J. B. (1983). In Mammalian Thermogenesis, pp. 99-140 [L. Girardier and M. J. Stock, editors]. London: Chapman \& Hall.

Leathwood, P. D. (1987). Proceedings of the Nutrition Society 46, 143-156.

LeFeuvre, R. A., Rothwell, N. J. \& Stock, M. J. (1987). Neuropharmacology 26, 1217-1221.

Liebowitz, S. F. (1978). Pharmacology, Biochemistry and Behavior 27, 1031-1040.

McLaughlin, C. L. \& Baile, C. A. (1985). Physiology and Behavior 35, 365-370.

Morimoto, A. \& Murakami, N. (1985). American Joumal of Physiology 248, R84-R92. 
Morimoto, A., Murakami, N., Nakamori, T. \& Watanabe, T. (1988). Journal of Physiology 397, $259-268$. Myers, R. D. (1972). In Serotonin and Behaviour, pp. 293-309 [J. Barchas and E. Usdin, editors]. New York: Academic Press.

Myers, R. D., Hepler, J. R. \& Holahan, W. (1983). Peptides 4, 85-88.

Niijima, T., Rohner-Jeanrenaud, F. \& Jeanrenaud, B. (1984). American Journal of Physiology 247, R650-R654.

Oomura, Y. (1976). In Hunger: Basic Mechanisms and Clinical Implications, pp. 145-157 [D. Novin, W. Wyrwicka and G. Bray, editors]. New York: Raven Press.

Oomura, Y. (1987). News in Physiological Sciences 2, 199-203.

Perkins, M. N., Rothwell, N. J., Stock, M. J. \& Stone, T. W. (1981). Nature 289, 401-402.

Posner, B. I. (1987). Proceedings of the Nutrition Society 46, 97-103.

Rothwell, N. J. (1989). American Journal of Physiology 256, E111-E115.

Rothwell, N. J. \& Stock, M. J. (1981). Annual Review of Nutrition 1, 235-256.

Rothwell, N. J. \& Stock, M. J. (1986a). Bioscience Reports 6, 3-18.

Rothwell, N. J. \& Stock, M. J. (1986b). In Brown Adipose Tissue, pp. 269-298 [P. Trayhurn and D. G. Nicholls, editors]. London: Edward Arnold.

Rothwell, N. J. \& Stock, M. J. (1986c). Proceedings of the Nutrition Society 45, 111 A.

Rothwell, N. J. \& Stock, M. J. (1987). International Journal of Obesity 11, 319-324.

Rothwell, N. J. \& Stock, M. J . (1988). International Journal of Obesity 12, 93-102.

Rothwell, N. J., Saville, M. E. \& Stock, M. J. (1982). International Journal of Obesity 6, 53-57.

Rothwell, N. J., Stock, M. J. \& Thexton, A. J. (1983a). Journal of Physiology 342, 15-22.

Rothwell, N. J., Stock, M. J. \& Warwick, B. P. (1983b). International Journal of Obesity 7, $263-269$.

Sahakian, B. J., Trayhurn, P., Wallace, M., Deeley, R., Winn, P., Robbins, T. W. \& Everitt, B. J. (1983). Neuroscience Letters 39, 321-326.

Saito, M., Minokoshi, Y. \& Shimazu, T. (1987). Life Sciences 41, 193-197.

Seydoux, J., Llanos, Q. J. \& Blatteis, C. M. (1985). Federation Proceedings 44, 438.

Seydoux, J., Rohner-Jeanrenaud, F., Assimacopoulos-Jeannet, F., Jeanrenaud, B. \& Girardier, L. (1981). Pfugers Archiv 390, 1-4.

Shibata, M., Benzik, H., Seydoux, J. \& Girardier, L. (1987). Brain Research 436, 273-282.

Shimazu, T., Noma, M. \& Saito, M. (1986). Brain Research 369, 215-223.

Shimazu, T. \& Takahashi, A. (1980). Nature 284, 62-63.

Shiraishi, T. \& Mager, M. (1980). American Journal of Physiology 239, R265-R269.

Stanton, T. L., Winokur, A. \& Beckman, A. L. (1980). Brain Research 181, 470-475.

Stellar, E. (1954). Psychological Reviews 61, 5-22.

Tepperman, F. S. \& Hirst, M. (1983). European Journal of Pharmacology 96, 243-249.

Weingarten, H. P., Chang, P. \& McDonald, T. J. (1985). Brain Research Bulletin 14, 551-559.

Williamson, D. H. (1987). Proceedings of the Nutrition Society 46, 81-87.

York, D. A. (1987). Proceedings of the Nutrition Society 46, 105-117.

Yoshida, T., Kemmitz, J. W. \& Bray, G. A. (1983). Journal of Clinical Investigation 72, 919-927. 